\title{
THE ROLE OF SMALL AND MEDIUM- SIZED ENTERPRISES IN NUTRITIOUS FOOD SUPPLY CHAINS IN AFRICA
}

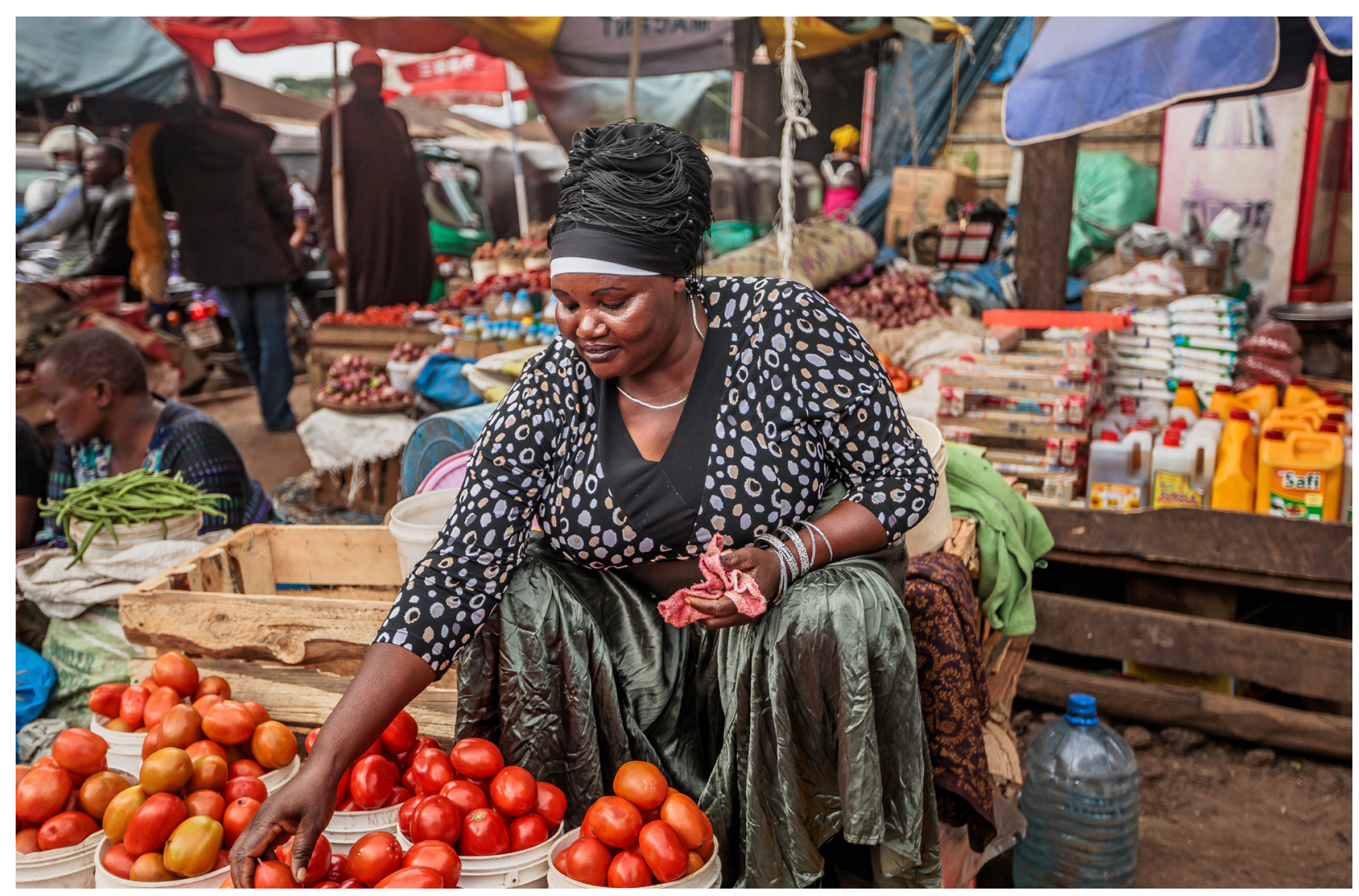

\section{GAIN Working Paper Series n²}

April, 2020

Kathrin M. Demmler

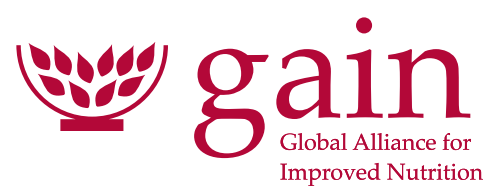




\section{ABOUT GAIN}

The Global Alliance for Improved Nutrition (GAIN) is a Swiss-based foundation launched at the UN in 2002 to tackle the human suffering caused by malnutrition. Working with governments, businesses and civil society, we aim to transform food systems so that they deliver more nutritious food for all people, especially the most vulnerable.

\section{Recommended citation}

Demmler KM. The Role of Small and Medium-sized Enterprises in Nutritious Food Supply Chains in Africa. Global Alliance for Improved Nutrition (GAIN). Working Paper Series \#2. Geneva, Switzerland, year. DOI: https://doi.org/10.36072/wp.2

\section{() The Global Alliance for Improved Nutrition (GAIN)}

This work is available under the Creative Commons Attribution-Non-Commercial-Share Alike 4.0 IGO licence (CC BY-NC-SA 4.0 IGO; https://creativecommons.org/licenses/by-nc-sa/4.0/). Under the terms of this licence, you may copy, redistribute and adapt the work for non-commercial purposes, provided the work is appropriately cited, as indicated below. In any use of this work, there should be no suggestion that GAIN endorses any specific organisation, products or services. The use of the GAIN logo is not permitted. If you adapt the work, then you must license your work under the same or equivalent Creative Commons license. The contribution of third parties do not necessarily represent the view or opinion of GAIN.

\section{Acknowledgements}

Special thanks go Daniel Alberts, Saul Morris, Lynnette M. Neufeld, and Stella Nordhagen (all GAIN) for their valuable comments to this Working Paper. I would also like to thank Joyce W. Gema for her contribution and ideas regarding structure and setup of this paper. The author also gratefully acknowledges the financial support of the Dutch Ministry of Foreign Affairs. All photographs included in this document have been taken with consent for use in publications. Cover photo $\odot$ GAIN / Brian Otieno.

\section{GAIN WORKING PAPER SERIES}

The GAIN Working Paper Series provides informative updates on programme approaches and evaluations, research, and other topics relevant to helping reshape the food system to improve the consumption of nutritious, safe food for all people, especially the most vulnerable.

The Global Alliance for Improved Nutrition (GAIN)

Rue de Varembé 7

1002 Geneva

Switzerland

T: +41227491850

E: info@gainhealth.org

www.gainhealth.org 


\section{SUMMARY}

Fighting malnutrition in all its forms is one of the major challenges of the $21^{\text {st }}$ century.

Addressing it will require an agricultural transformation. Within Africa, this must include a focus on small and medium-size farms, which provide about $80 \%$ of total calories in sub-Saharan Africa, as well as other small actors along the value chain.

This paper aims to inform this transformation by helping to illuminate the role and dynamics of SMEs along African food value chains, including production, processing, and retailing. Differentiating between fruits and vegetables (FV), animal-source foods (ASF), and cereals and legumes, this paper finds that SMEs are important at each stage of the food value chain and for each commodity type. SMEs are responsible for over half of the production of FV, ASF, and cereals and legumes. For processing of these food groups, the picture is more ambiguous and highly dependent on the commodity and type of processing. At the retail stage, however, $70 \%$ to $100 \%$ of foods are sold through SME channels.

Overall, the data on SMEs in Africa is scarce. However, it is clear that although the shares of ASF and cereals being processed and marketed by large enterprises and modern retailers are increasing, SMEs still play an important role throughout the African food value chain, including production, processing, and retail and particularly for low-income consumers. Therefore, SMEs should be included in any public- or private-sector efforts to increase the availability, accessibility, and affordability of nutritious foods.

\section{KEY MESSAGES}

- SMEs are highly involved in the production, processing, and retailing of fruits and vegetables, animal-source foods, and cereals and legumes in Africa.

- The retail sector is dominated by SMEs, which play an important role in ensuring the availability and affordability of foods, particularly for low-income populations.

- SMEs should be a focus of any public- or private-sector efforts to increase the availability, accessibility, and affordability of nutritious foods.

- Infrastructure development and urban planning provide opportunities to ensure consumers have access to affordable nutritious foods, support informal food vendors' livelihoods, and reduce food loss.

- Policy and regulatory frameworks will be needed to ensure the availability of raw commodities while allowing the SME food processing sector to grow and add value to markets and economies.

- More differentiated data on SMEs' involvement in each value chain stage are needed to draw a clear, representative picture of SMEs in Africa. 


\section{BACKGROUND AND OBJECTIVE}

Fighting malnutrition in all its forms is one of the major challenges of the $21^{\text {st }}$ century. While more than 820 million people suffer from undernutrition and hunger, with 150 million children under age 5 being stunted, another 2 billion people are overweight or obese (1). Some achievements have been made, especially in addressing childhood malnutrition-the prevalence of stunting in children under 5 has been reduced by about $32 \%$ in the last 20 years; however, progress in fighting malnutrition in all its forms is happening too slowly to achieve the Sustainable Development Goals (SDGs) by 2030 (2).

A growing world population, rapid urbanisation, income growth, and changing diets are putting food systems ${ }^{1}$ under heavy pressure as they struggle to provide affordable, available, nutritious, safe, and sustainable foods for all. While there has been significant progress in increasing world food production, the Food and Agriculture Organization of the United Nations (FAO) estimates that a further $50 \%$ increase in food production by 2050 will be needed to feed a growing world population a nutritious, safe, and sustainable diet (4). There is an increasing need for food production and processing in order to increase food safety and reduce food losses. Retail is also important in affecting people's nutrition: informal food markets remain relevant, particularly for low-income households, but the rapid spread of supermarkets poses new challenges and opportunities for the food system, food producers, processors, and consumers (5).

While it is often assumed that global food production mainly relies on large-scale farms and industries, in many contexts reality shows a different picture. Out of the 570 million farms worldwide, $84 \%$ are smallholder or micro farmers, with land sizes less than or equal to 2 hectares (6). These farms operate about $12 \%$ of agricultural land (6), and, together with medium-sized farms (2-20 ha), they provide almost half of total calories worldwide (7). Besides producing foods, small- and medium-sized enterprises (SMEs) play an important role in food processing and retail-and thus in the overall food value chain.

While some evidence exists of the importance of SMEs in Africa (8-11), the role and dynamics of small- and medium-sized farms and enterprises along the food value chain are little understood. This paper aims to provide an understanding of SMEs' involvement in the food supply chain, with a focus on certain highly nutritious foods. First, it examines the role of SMEs in the production, processing, and retailing of different food groups in Africa. ${ }^{2} \mathrm{Next}$, the dynamics between the different stages of the food supply chain and the flow of foods produced by SMEs and others along these stages are discussed, highlighting the relevance of SMEs for the end consumer. The paper concludes by offering recommendations of how to better support SMEs across the value chain.

\footnotetext{
1 "A food system gathers all the elements (environment, people, inputs, processes, infrastructures, institutions, etc.) and activities that relate to the production, processing, distribution, preparation and consumption of food, and the outputs of these activities, including socio-economic and environmental outcomes." (3)

2 This working paper focusses on Africa and tries to display results for the whole continent. However, due to limited data availability, some results only relate to Sub-Saharan Africa.
} 


\section{METHODOLOGY}

This article summarises available literature on small- and medium-size enterprises and producers and their involvement along the food value chain, with a focus on the African continent and African countries. ${ }^{3}$ Literature was searched between September 2019 and February 2020 using PubMed and Google Scholar and complemented with key reports and publications of international organisations. ${ }^{4}$ Terms used for the literature search included "small medium enterprise"; "small medium producer"; "SME"; "SMEs"; "business" and/or "food value chain"; "value chain" and "Africa"; "Sub-Saharan Africa." There was no publication date restriction, and the search was limited to English-language results. While there are some analyses of the production of small- and medium-size farms at the continental level that could be used (see 7), this paper mainly relies on data from single studies and countries.

\section{DEFINING SMES ALONG THE FOOD SUPPLY CHAIN}

Food supply chains include all actors and activities that are needed to provide and move food from producers to consumers (12)including agricultural production, processing, storage, marketing, distribution, and consumption. FVCs are changing rapidly in developing countries (DCs. This includes preparatory steps, like the supply of inputs and other farm-preparation activities, as well as food production, harvesting, storage, transport, processing, packaging, marketing, and retail. Due to limited data availability for certain aspects of the food value chain, this article focuses on the production, processing, and retail stages, as illustrated in Figure 1.

At each stage of the supply chain analysed here, micro-, small-, medium-, and large-scale actors are involved. All activities along the food supply chain influence the four dimensions of food security and nutrition-availability, accessibility, utilisation, and stability-and also affect the nutritional value of food (3).

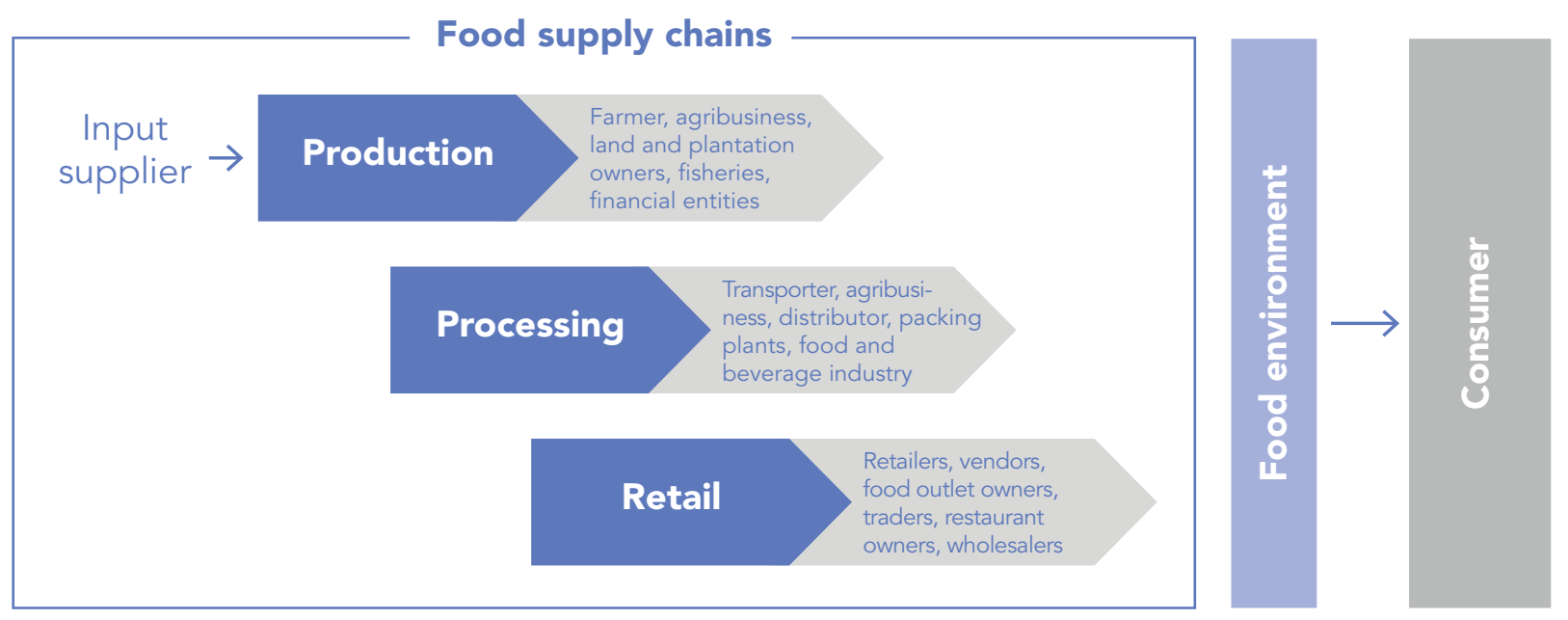

Figure 1. The three stages of food supply chains. Own illustration based on $(3,13)$.

\footnotetext{
3 Although the term 'SME' is often used, there is no standard international definition of an SME, since classifications strongly depend on the local (economic) environment. While some of definitions are based on size, capital assets, skill of workers, and turnover level, others use legal status and method of production. Most commonly the size of businesses in terms of amount of labour is used. For the production stage, plot sizes are also used. The definition of a food value chain SME used here includes any business that produces, stores, distributes, processes, packages, or retails food, whether in a rural or urban context. This includes small- and medium-sized producers (i.e. farmers).

4 Including the Food and Agriculture Organization of the United Nations (FAO), International Food Policy Research Institute (IFPRI), Global Alliance for Improved Nutrition (GAIN), Scaling Up Nutrition Movement (SUN), and World Bank.
} 


\section{TYPES AND AMOUNTS OF FOOD PRODUCED BY SMES}

\section{SMES AT THE PRODUCTION STAGE}

The production stage shapes food availability and affordability, as well as food quality and diversity in a given food system. Actors at the production stage include farmers (who run and own their businesses) but also agribusinesses, which consist of an owner and various employees engaged in production. Micro farms ${ }^{5}$ are normally defined as having less than 2 ha of land, with the definition sometimes extending to those with up to $5 \mathrm{ha}$; depending on the context, small and medium-sized farms are defined as those with landholdings of 2-100 ha, 5-100 ha, or as $<50$ ha $(7,14)$. For this paper, micro farms are defined as having under 2 ha of land, and small and medium-sized farms as having 2-20 ha land, as African farms tend to be smaller than those in Europe, North and South America, and Oceania $(15,16)$. Every producer with a farm size over 20 ha is considered a large producer. Examples of small and mediumsized African farms are shown in Figure 2.

Depending on the type of food considered, small and medium-sized farms $<20$ ha produce between $30 \%$ and $65 \%$ (by volume) of global food for human consumption. While oil and sugar crops are mainly produced by larger farms ( $>50 \mathrm{ha})$, cereals, fruits, legumes, roots, tubers, and vegetables are mostly produced by small and medium-sized farms ( $<20$ ha) (7). For subSaharan Africa (SSA), the shares of major food crops produced by small and medium-sized farms is even larger: on average, about $75 \%-90 \%$ of all commodities in SSA are produced by farms $<20$ ha (7).
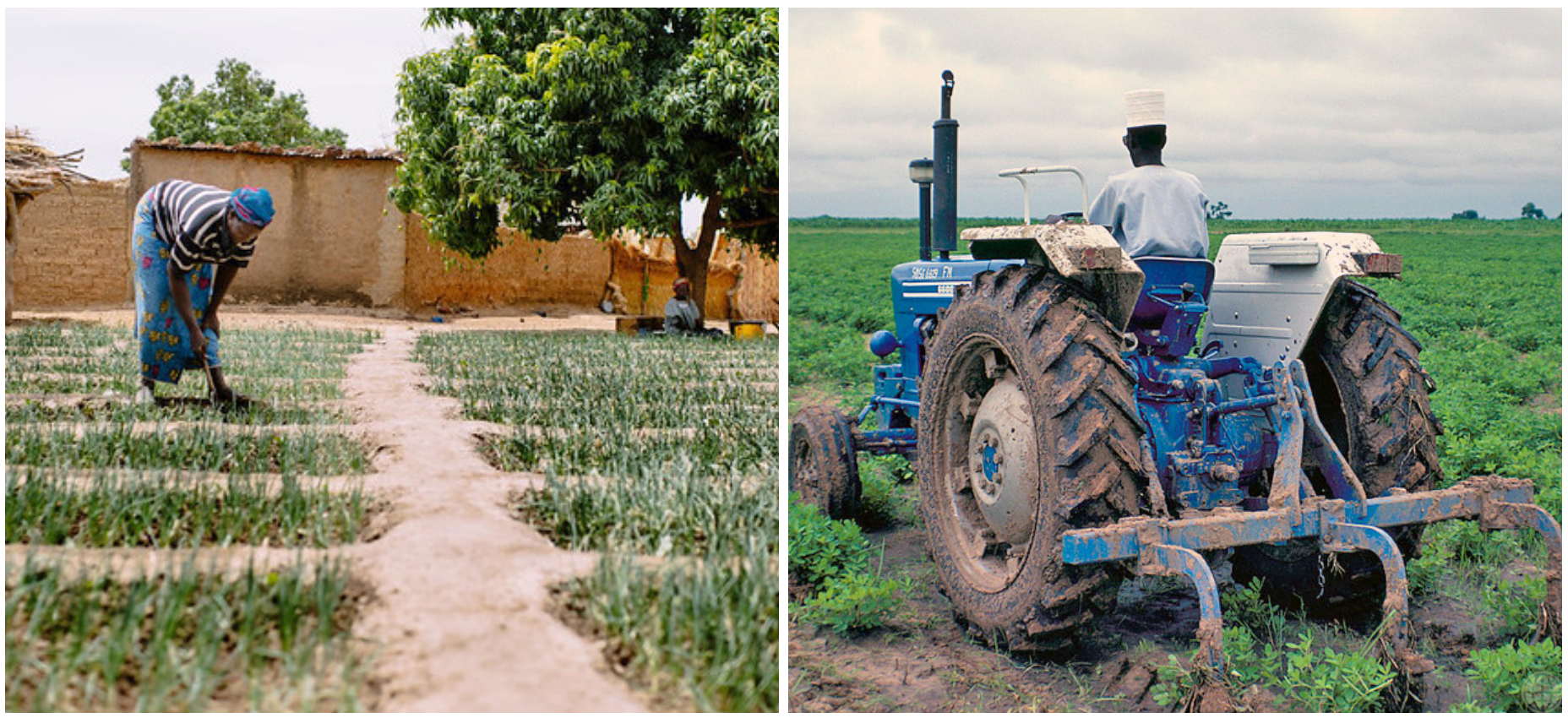

Figure 2. Left side: Small plot size farmer, Burkina Faso $(\subset)$ CIFOR; Right side: Medium plot size farmer, Nigeria @ World Bank

5 Smallholder farmers are also considered to be in the micro farms category. 


\section{FRUITS AND VEGETABLES}

Fruits and vegetables (FV) are an essential part of healthy diets, due to their high micronutrient and dietary fibre content (17). Diets low in FV increase the risk of several major diseases and are one of the top five dietary risk factors worldwide (18). According to the reference diet suggested by Willett et al. (19), considering both health and environmental aspects, about $500 \mathrm{~g}$ of FV should be consumed by each adult every day. Aside from the Middle East and North Africa, no region currently meets this recommendation (19).

In SSA, over $85 \%$ of FV (by volume) are produced by micro and small and medium-sized farms ( $<20 \mathrm{ha}$ ), with small farms ( $<2 \mathrm{ha}$ ) producing just over $30 \%$ and farms between $2-20$ ha producing over $50 \%$ (7) (Figure 3). The shares produced by larger-sized farms (>20 ha) and very large farms (up to $200 \mathrm{ha}$ ) are much smaller, each being below $10 \%$. The dominance of micro and small/medium farms is in contrast to regions like Australia and New Zealand and North and South America, where the majority of FV (75-90\%) is produced by farms over 50 ha (7).

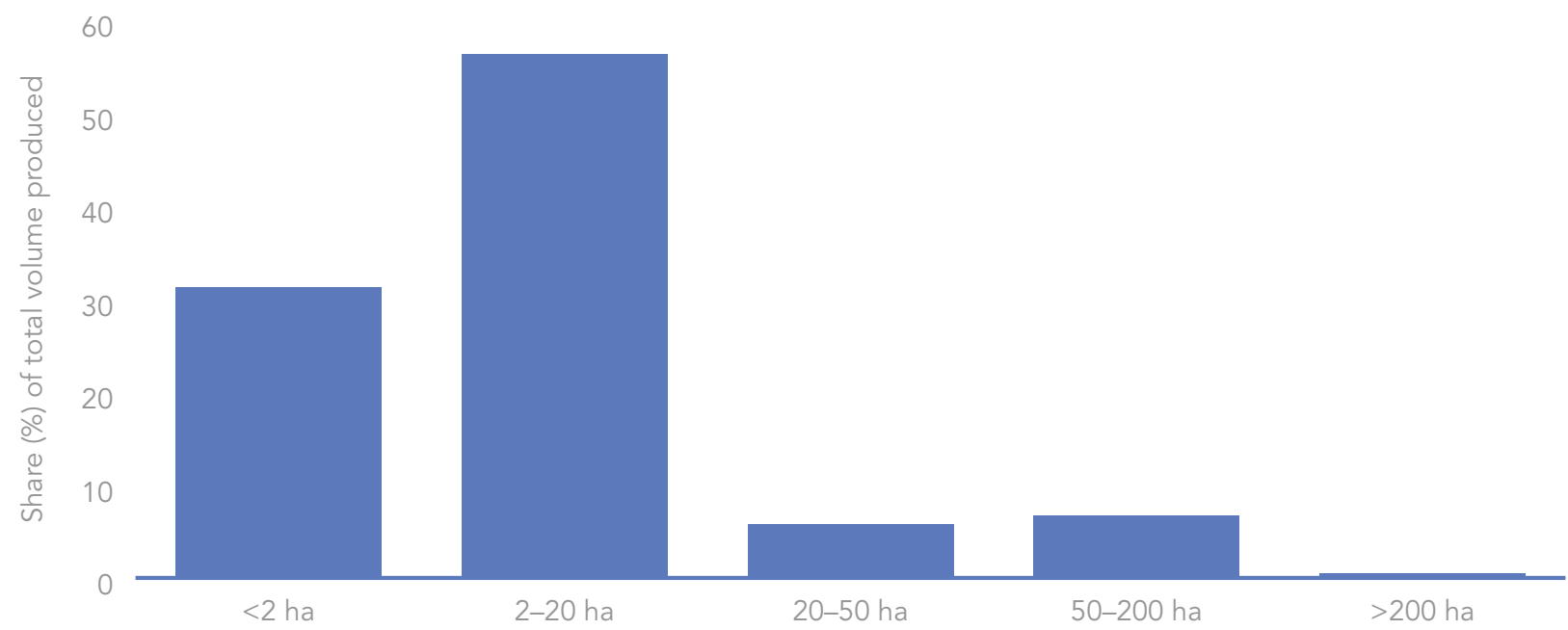

Figure 3. Share of fruit and vegetable production by different sized farms in SSA. Figure shows combined shares for both fruits and vegetables. ${ }^{6}$ Source: Own illustration based on graphs in Herrero et al. (7).

\section{ANIMAL-SOURCE FOODS ${ }^{7}$}

While global consumption of red meat is high-about 2.5 times that recommended by the EAT Lancet reference diet based on consideration of health and environmental effects-average meat consumption in SSA just barely meets the commission's modest recommendations (19). Moreover, over $60 \%$ of African countries have lower average meat supply than the African average, and about one fifth do not even meet half of the African average supply amount. ${ }^{8}$ While highly processed red meat consumption has been associated with increased risk of death

6 Fruits and vegetables include apple, banana, date, grapefruit, grape, orange, pineapple, plantain, onion, tomato, and not further specified citrus, fruit, and vegetables (7).

7 While fish are an important source of many nutrients, due to limited data availability, this chapter focuses only on meats, dairy, and eggs and does not include fish.

8 Shares are based on data by FAOSTAT (20), Food Balance Sheets, food supply (g/pp/d) of total meats, 2017. Countries having a meat supply of less than $50 \%$ of the average African supply include Ethiopia, Nigeria, Gambia, Sierra Leone, Rwanda, Tanzania, Mozambique, and Uganda. 
and certain noncommunicable diseases (21), minimally processed meat and other animalsource foods (ASF-such as eggs, dairy, and fish) can also be a key component of nutritious diets. In particular, young children often cannot obtain adequate nutrients from plant-based foods alone, making ASF crucial for child growth and cognitive development $(22,23) .{ }^{9}$ While the nutrition and health value of ASF varies by type of food, due to data limitations, all landbased ASF (meat, eggs, and dairy) are jointly examined here.

In Africa, most livestock are kept in extensive systems by pastoralists and smallholders using traditional management practices and pursuing subsistence rather than market objectives. Most livestock owners in Africa reside in arid and semi-arid areas and have only small numbers of animals $(24,25)$. Only $5-20 \%$ of livestock production in Africa is for commercial purposes; ${ }^{10}$ the rest is mainly produced for subsistence rather than market objectives (25). While the African milk market is dominated by Eastern and Northern African countries, the meat and egg market, including beef, pork, and poultry, is dominated by the Southern and Western regions (26). Across the continent, about $80 \%$ of ASF, including milk and eggs, is produced by micro and small and medium- sized farmers $<20$ ha (7) (Figure 4). About $15 \%$ of meat and ASF in Africa is produced by larger farms (20-200 ha) (7), partly driven by large dairy farms in South Africa (27).

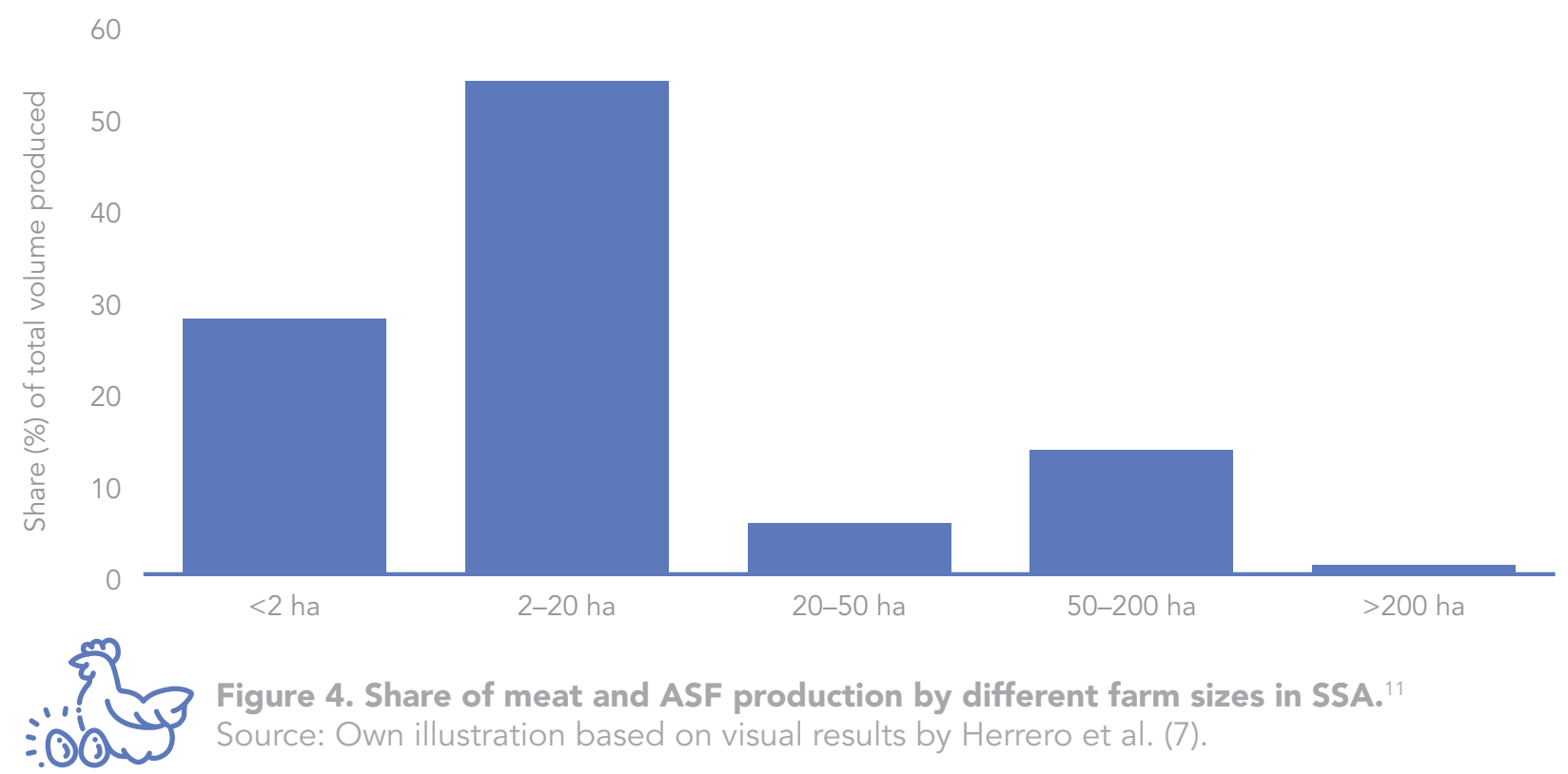

9 Based on the advantages of certain types of ASF (especially eggs, dairy, and fish) and the disadvantages of highly processed meats, any discussion on the role of ASF in promoting health and nutrition needs to be somewhat nuanced.

10 Commercial purposes here imply taking active measures to achieve higher yields per animal, e.g. through appropriate inputs (25). 11 Meat and animal source products include bovine meat and milk, sheep and goat meat, sheep and goat milk, pork, eggs, and poultry meat (7). 


\section{CEREALS AND LEGUMES}

While some traditional cereals (e.g. pearl millet, finger millet, and teff) are still grown, maize, rice, sorghum, and wheat now dominate cereal production in Africa (28). Overall, maize is the most demanded and produced staple at the continental level, accounting for $45 \%$ of total major crop production by volume in 2017 (28). ${ }^{12}$ African legumes include cowpeas, pigeon peas, chickpeas, mung beans, dolichos, lentils, vetches, Bambara beans, broad beans, groundnuts, and soybeans. In 2018, about $40 \%$ of the legumes production in Africa ${ }^{13}$ was comprised of vetches (different types of legumes), broad beans, and chickpeas (28). Cereal and legume production in Africa mainly rely on micro and small and medium-sized farms ( $<20 \mathrm{ha})$, which provide over $85 \%$ of total cereal and legumes production (Figure 5). For cereals, many African countries also rely on imports: over $18 \%$ of maize and almost $60 \%$ of wheat supplies were imported in 2013 (29).

Looking across all food groups presented here, the involvement and importance of small and medium-sized producers is very clear. While micro farmers ( $<2 \mathrm{ha})$ produce about one third of the total production of these food groups, the majority (about $55 \%$ ) is produced by small and medium-sized producers. For some food groups, including dairy and meat, large producers ( $>20-$ $200 \mathrm{ha}$ ) are also important, providing about $20 \%$ of total livestock production of the continent (7).

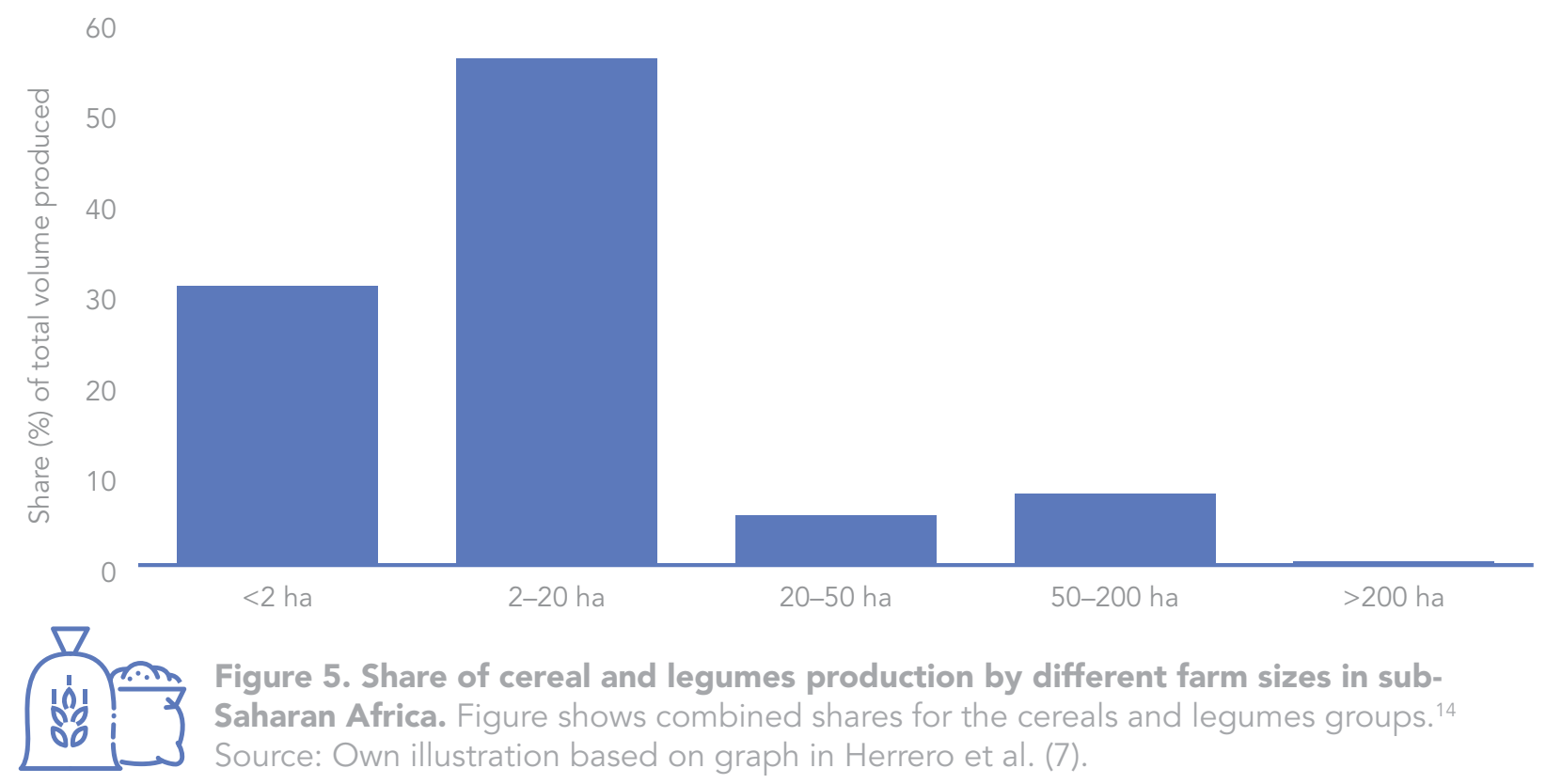

12 Major crops considered here include maize, millet, rice (paddy), sorghum, and wheat, with a total production amount of 188 million tonnes in 2017 (28).

13 This estimate does not include groundnuts and soybeans as per FAOSTAT's definition of legumes.

14 Cereals include barley, maize, millet, oats, rice, rye, sorghum, wheat, and cereals (not further specified). Legumes include bean, pea, and other non-specified types of legumes (7) 


\section{TYPES AND AMOUNTS OF FOOD PROCESSED BY SMES}

\section{SMES AT THE PROCESSING STAGE}

For firms, as opposed to farms, size is typically defined based on number of employees or sales revenue. For LMICs, the United Nations Industrial Development Organization (UNIDO) defines micro-sized firms as employing fewer than 5 workers, small firms as those with 5-19 employees, and medium-sized firms as those with 20-99 employees (10). Since most African countries are $\mathrm{LMICs}^{15}$, where possible this paper will use this definition for SMEs at the processing and retail stage.

The processing stage is very relevant for food quality and safety since appropriate storage and transportation (e.g. cold chains) help avoid food contamination and lessen post-harvest nutrient loss in fresh products. In SSA, food loss and waste due to poor harvesting practices, post-harvest losses, and inadequate packaging and processing account for about one third of all food produced (31). Furthermore, food processing (e.g. through milling, cooking, freezing, fermentation, or fortification) can increase shelf-life, food palatability and convenience, and nutrient content $(32,33)^{16}$ Actors at the processing stage include food processors, which can be businesses of any size ranging from subsistence microprocessors to small/medium and large businesses (Figure 6). Food industries do not include subsistence microprocessors, but rather labour- and capital-intensive, often highly mechanised industrial processes that can include collectives of different businesses (36). Overall, this midstream segment constitutes about $40 \%$ of total value in the agri-food value chain in Africa (9).

Agri-food processing in Africa has experienced great expansion in recent years. Factors enabling change include agricultural intensification, commercialisation, and diversification beyond basic grains. Also, liberalisation and privatisation of the so-called midstream value chain segments has led to massive investments by SMEs and large enterprises in supply chains. Overall, it is estimated that $80-90 \%$ of agri-food processing is in a "transitional" stage ${ }^{17}$ with many SMEs engaged in wholesale, logistics, and processing (9).

15 As of 2019, the World Bank defines countries with per capita Gross National Income below USD 1,025 and USD 3,995 as lowand lower-middle-income countries, respectively. Based on the World Bank List of Economies (30), of 48 African countries, 85.4\% fall in the low- or lower-middle-income group.

16 Of note, high levels of processing may also increase the levels of sodium, saturated fats, and sugar in food products and decrease the amount of fibre and key nutrients $(34,35)$

17 The transitional stage is characterised by the expansion of value chains stretching into rural areas to supply cities during rapid urbanisation (9). 
In high-income countries, $98 \%$ of all agricultural production is industrially processed. In LMICs this share is much smaller, accounting for only $30 \%$ of production and $40-60 \%$ of all manufacturing value generated in the agro-processing industry (37). However, African SMEs in the wholesale, logistics, and processing stages of the food value chain have grown rapidly and will continue to play a key role in African food systems over the next 10-20 years (9). While it is estimated that SMEs comprise about $80 \%$ of the total number of enterprises involved in the midstream food value chain in SSA (9), the actual level of involvement of SMEs in the midstream of the food value chain is largely a black box and highly dependent on the commodity, type of processing, and local conditions and regulations.

This section has jointly considered first-stage processing (cleaning, grading, dehusking, and milling) and second-stage processing (cooking, freezing, fermentation, oil hydrogenation, fortification (see Box 1 for details), and other advanced modifications to raw products), making the range of activities and commodities considered very broad. To draw a clearer picture of the involvement of SMEs in processing, the following sub-sections will focus on examples of specific processing activities and commodities.

\section{BOX 1: FORTIFICATION}

One type of processing is food fortification, the practice of adding one or more nutrients to a food. It is seen as one of the most efficient ways to improved nutrient intake at a population level (38). Most food fortification is done by large firms. This is partly because numerous quality and practical issues are involved with fortifying food at the small and medium-scale level. Moreover, politics and laws often impede the participation of SMEs in fortification. In some instances, penalties for non-adherence to national mandatory fortification standards discourage the involvement of small and medium-size processors. To mitigate this, some national fortification laws exclude small and medium-sized processors. In Uganda, for example, only firms processing over 20 metric tons per day of maize or over 10 metric tons per day of oil are considered under the fortification law (39). In Tanzania, for all food vehicles (except salt) micro and small-scale enterprises are exempt from the fortification legislation, although the legislation does not define micro or smallscale enterprises further (40).

Furthermore, the involvement of SMEs in fortification in Africa varies highly by food vehicle. While the fortification of maize flour involves thousands of small-scale millers, salt fortification can be fully centralised ${ }^{18}$ (e.g. Nigeria), almost fully centralised (e.g. Kenya), or done by a combination of SMEs and large businesses (e.g. Mozambique, Ethiopia, and Tanzania). Similar variation in the involvement of SMEs and large enterprises is seen for wheat flour and oil fortification. While wheat flour fortification is generally highly centralised, there are exceptions; in Ethiopia, for example, there are over 300 mostly small-scale wheat mills (41).

18 Centralised fortification is characterised by a structure involving only a few, large-scale processors. 


\section{FRUITS, VEGETABLES, CEREALS, AND LEGUMES}

Most FV in Africa are marketed in unprocessed forms or consumed by the producing households. For example, data from the Zambezi valley and South Africa show that $80-94 \%$ of indigenous fruits are home-processed into beer, jam, and juice for direct consumption (42). In the rare cases where FV are processed, large-scale firms play an important role. In Kenya, for example, less than 7\% of FV (2005 estimate) are processed by national food companies, with the main products being canned tomatoes, processed tomato and chilli sauces, or tomato paste. While small and medium-scale processing happens for similar products, the volume is estimated to be small and data is scarce (43).

While processing of FV is rare and mainly depends on home processing, cereals and legumes are processed at higher levels. For example about $60-70 \%$ of beans and cowpeas at a continental level are consumed by the producing households, but levels are slightly lower in Ghana and Nigeria, where 32\% and 56\%, respectively, of cowpeas are consumed by the producing households (44). Data from Kenya, Ghana, and Nigeria show that between 50$80 \%$ of groundnuts and soybeans are processed and marketed in the form of dried and or manufactured grains. Presumably this processing is done at home or through SMEs, as examples from Kenya depict that processing of groundnuts happens mainly through informal household enterprises (e.g. into peanut butter). However small amounts of cowpeas are also processed, branded, packed in private retailer labels, and sold through supermarkets (44).

Other examples clearly show the involvement of SMEs. In Tanzania, for example, maize flour production mainly relies on SMEs, which mill 95\% of the total maize flour in the country (45). However, depending on the country and product, large-scale businesses can also have large shares in the processing of cereals and legumes; examples include oilseed processing and grain milling in Zimbabwe (9), but specific data are missing.

\section{ANIMAL-SOURCE FOODS}

In most African countries, industrial and semi-industrial meat processing is very limited. In Ethiopia, for example, there is only one large public slaughterhouse, which slaughters about 1,200 cattle, 1,500 sheep, and goats each day. In addition, there are several smaller private slaughterhouses, which combined slaughter a similar number of cattle. Taking all these (semi-) industrial meat processors together, their share in meat processing is likely below $5 \%(46) .{ }^{19}$ This suggests a large role for home/microprocessors and SMEs (e.g. local butchers and abattoirs).

Considering dairy products, milk in Africa is predominantly consumed fresh with limited processing into other products like cheese, butter, or yoghurt. Overall, about $10 \%$ of milk is processed into fresh milk products, $15 \%$ is processed into cheese, yogurt, butter, and similar, and about $60-70 \%$ is consumed unprocessed or home processed at farm level or traded in unprocessed form through informal markets $(47,48)$.

19 Estimated based on the fact that these processors jointly slaughter about 600,000 cattle annually, which is only $1 \%$ of the total stock of 55 million head of cattle in Ethiopia (46). 
In many African countries, the processing of higher-value dairy, including butter, milk powder, and cream, is done by large enterprises. In Uganda, for example, the share of milk that is sold unprocessed or consumed directly at farm level is about $60 \%$, while the rest is processed into higher-value products. Most of this processing ( $95 \%$ of all processed milk) is facilitated by nine large companies, which have an average processing capacity of $288,500 \mathrm{~L} /$ day. SMEs have much smaller capacities, an average of $545 \mathrm{~L} /$ day for small firms and 3,580 L/day for medium-sized firms, and account for less than $5 \%$ of the market share in Zambia's high-value dairy processing sector (49). In Ethiopia, dairy processing is mainly facilitated through informal markets, which account for $35 \%$ of the yoghurt, $55 \%$ of the milk, $75 \%$ of the cheese, and $85 \%$ of the butter processing. Formal SMEs contribute slightly smaller shares to the processing of drinking milk (26\%), cheese (18\%), yoghurt (15\%), and butter (12\%). Large enterprises have a comparably large share in the processing of yoghurt (50\%) but a smaller share of drinking milk (19\%) and particularly cheese (7\%) and butter (3\%) (Figure 7) (50).

Overall, it can be assumed that most of the milk in Africa is either not processed or processed at home. However, for higher-value dairy products, including yoghurt and cheese, SMEs and large enterprises are both relevant actors, with their shares highly dependent on the product and location. Given the lack of data at the continental level, particularly for meat and livestock, the discussion here of detailed data on ASF focuses on the milk and dairy sector in selected countries.

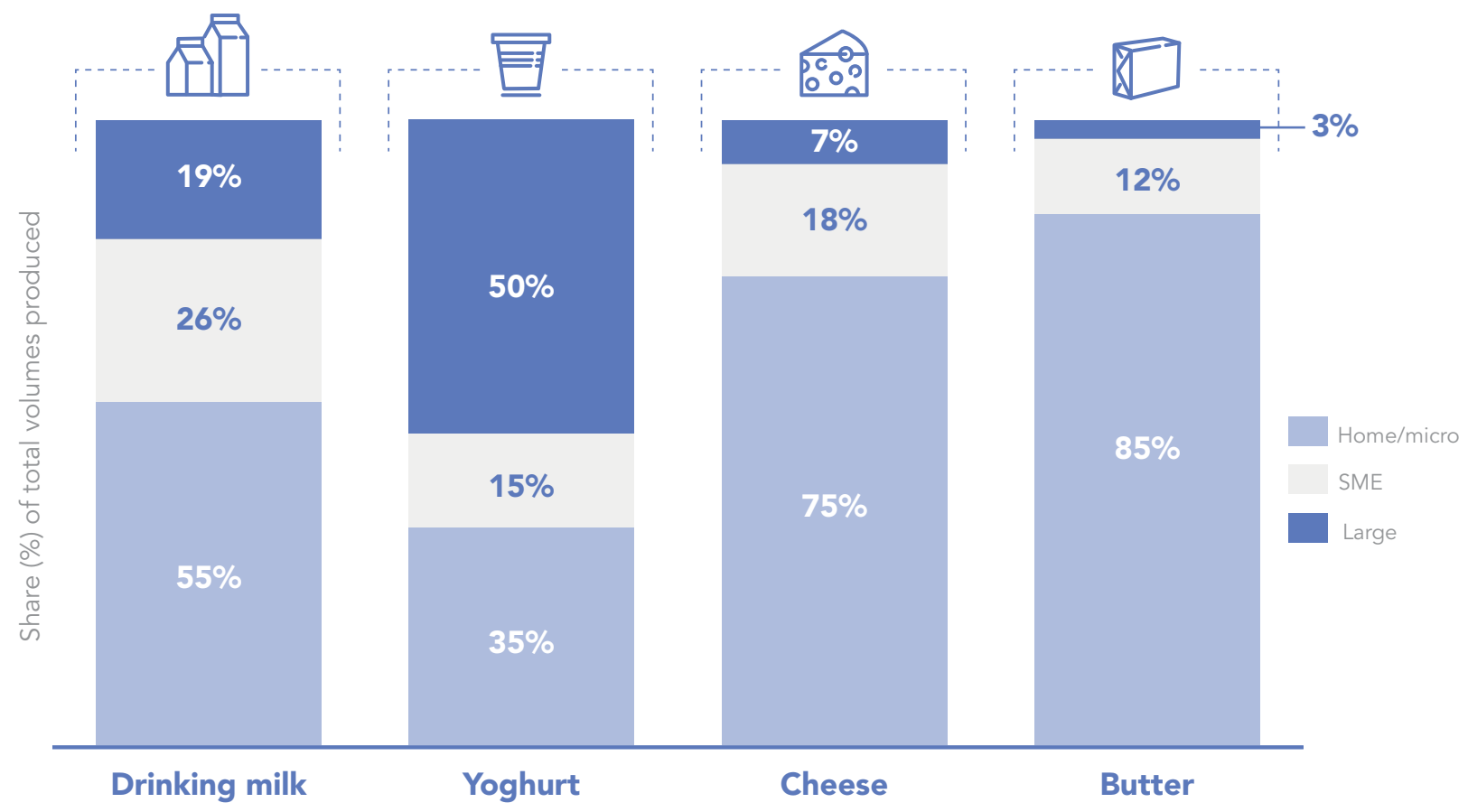

Figure 7. Shares of different size processors of milk and dairy products in Ethiopia. Own illustration, data based on Euromonitor (50). 
Besides these local enterprises, multinational companies (e.g. Nestlé (CH), Lactalis (F), Danone $(\mathrm{F})$, Friesland Campina (NL), Arla Foods (S), and Sodiaal (F)) are increasingly shaping the African dairy market. Danone, for example, partnered with the Abraaj Group (Dubai) in 2013 to acquire $49 \%$ of Fan Milk International, a company active in West Africa for decades; in so doing, they gained access to a network of 30,000 milk suppliers using bicycles and carts across six countries (Benin, Burkina Faso, Ivory Coast, Ghana, Nigeria, and Togo, with an estimated reach of 250 million people) to deliver ice cream products made from imported milk powder. In Senegal, milk powder has long represented much of milk consumption. Major dairy companies have set up partnerships, including with SMEs selling milk powder and other dairy products in the country. Domestic supply, however, is not always sufficient. In Senegal, over 55\% of milk and dairy products were imported in 2013 (51). Since 2014, Danone's milk powder has contributed up to $50 \%$ of Senegalese milk imports, in order to meet increasing demand (52).

Since the processing stage, as defined for this paper, is characterised by a broad range of activities and actors, and as processing depends highly on the commodity and local circumstances, it is difficult to make a general conclusion on the involvement of SMEs. For some food groups, processing does not play a major role; fruits and vegetables, for example, are often unprocessed or home processed. For meat and other ASF, the type of processor varies widely: while higher-value dairy products are often processed through large enterprises, meat is still mostly processed at home or through SMEs. For cereals, SME involvement depends strongly on the crop and local context.

\section{TYPES AND AMOUNTS OF FOOD SOLD THROUGH SMES}

\section{SMES AT THE RETAIL STAGE}

The retail stage entails foods being sold to consumers. The main actors here are markets, supermarkets, small shops and stores, individual food vendors, and restaurant owners. The characteristics of food retail outlets, including their location, prices, and promotions, influence consumers' food choices, consumption patterns, and, through this, their nutrition and health $(3,53,54)$. Retail SMEs include traditional food outlets, which mainly operate informally and include local markets, 'mom and pop' stores, roadside vendors, and hawkers, as well as small shops and groceries (typically classified as types of 'traditional retail') (Figures 8, 9). The large enterprises at this stage are all types of 'modern retail' and encompass restaurants (including fast food), and modern supermarkets or hypermarkets, most of which are chain stores $(8,50,55,56)$ (see Box 2 for further details on the differentiation of retail outlets). Although traditional food outlets often operate within the informal sector, ${ }^{20}$ retail SMEs are not informal per se. There are also many small shops and groceries with formal status (i.e. registered businesses that pay taxes). However, since large retail businesses are always considered to hold formal status, this paper assumes that informal retailers can all be categorised as SMEs (57).

20 An informal business is characterised by being unregistered, not paying taxes, bargaining prices with costumers, and having less credibility and/or quality assurance than formal businesses (57). Furthermore, informal markets often are not subject to effective health and safety regulations (58). 


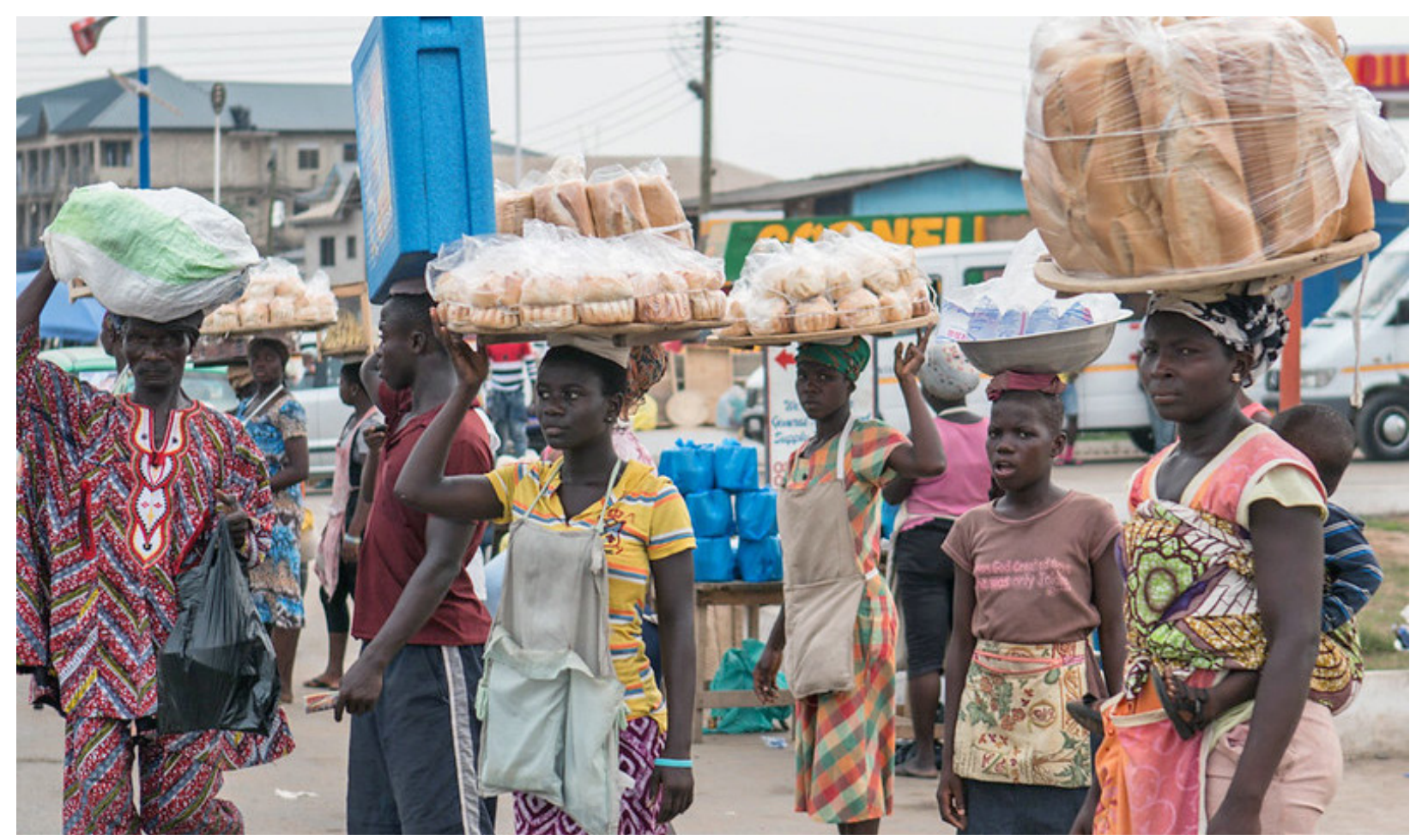

Figure 8. Picture: street food vendors, Ghana (C) Carsten ten Brink

While traditional outlets are still the most common food retailers in Africa's rural areas and low-income zones, modern retailers have spread across the continent, driven by several interconnected forces, including increasing incomes, urbanisation, greater female labour force participation, and lifestyle changes (59). Since 1990, the so-called 'supermarket revolution' (i.e. the emergence of modern retailers and large processors in large and small cities) has spread rapidly, and supermarkets currently account for $10-20 \%$ of the urban African retail economy $(9,60)$.

Overall, food retail represents about 20\% of the total value of the agri-food value chain in SSA. Accordingly, the sector and its functions are very important for consumers' food security as well as for farmers and other up-stream actors who provide their goods to retailers (9).
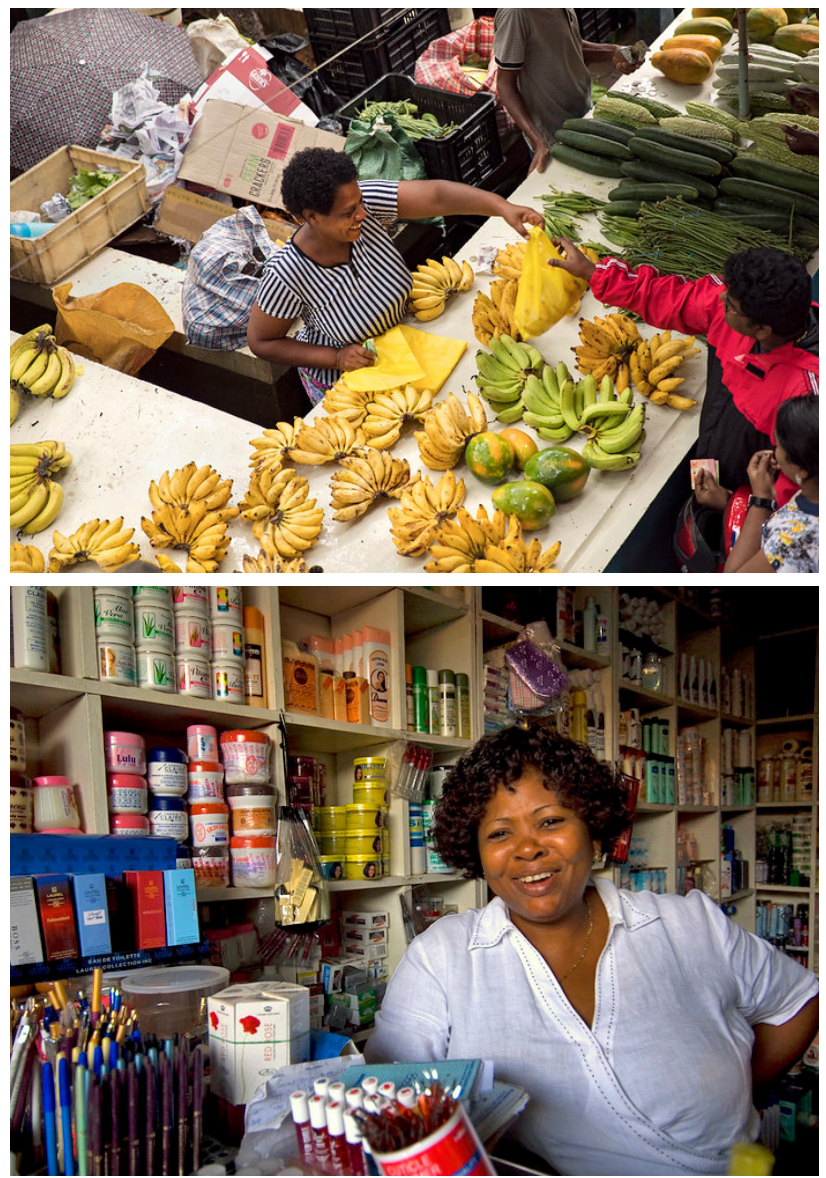

Figure 9. Picture (above): daily market retailer, Seychelle CUN Women; picture (below): small shop retailer, Ghana (C) World Bank 


\section{BOX 2. DIFFERENT RETAIL FORMATS}

The different types of retail outlets can be characterised by floor space, number of cash tills, type of service offered (self-service or over the counter), credit facilities, media promotions, product ranges, and offered package sizes. While traditional outlets tend to have small floor spaces (typically 10-30 m2), and no or very few (modern) cash tills with over-the-counter service, they often offer their customers the option buy on creditwhich can be important for low-income consumers. While the offered product and brand range can be rather limited, the variety of fresh FV sold can be large (61). Furthermore, package sizes range from very small units to large ones, increasing affordability for lowincome customers. While there are huge differences between types of traditional outlets, a common concern with informal markets is food safety. Limited infrastructure and facilities in traditional outlets (e.g. no toilets, proper flooring, or waste regulations) plus limited awareness and knowledge amongst sellers regarding food safety practices (e.g. hygiene, proper work clothing, handling of utensils, packaging) increase the risk for food contamination and hazards $(58,62)$.

The modern sector is associated with changes in store location, shopping atmosphere, a year-round wide assortment of products, and different brands, products, and package sizes $(55,61)$. Furthermore, modern outlets often profit from economies of scale, enabling the production, marketing, and distribution of foods (particularly packaged foods) at low per-unit prices (8). Overall, the number of supermarkets is growing, and this is affecting both producers and consumers, with profound implications for food consumption, nutrition, and health $(53,54,60,63,64)$.

\section{FRUITS AND VEGETABLES}

Despite the ongoing supermarket revolution (48) in many African countries, the sale of fresh FV is still mainly through traditional outlets (54). According to Gomez and Ricketts (8), over $90 \%$ of all FV in Kenya and Zambia are purchased in traditional retail outlets. Wanyama et al. (56) underline these findings, depicting that among poor households in Nairobi and Kampala up to $100 \%$ of FV are purchased through traditional outlets, mainly local markets, hawkers, and kiosks.

\section{ANIMAL-SOURCE FOODS}

Like FV, meat and dairy in Africa are mainly sourced through traditional retail outlets. In Ethiopia, $90 \%$ of households (particularly low-income households) buy their beef from local butchers at daily markets, while only about $14 \%$ of households also use supermarkets as a source (8). For poor urban households in Kampala, all meat purchases were found to be from traditional outlets, mainly local markets, roadside vendors, and kiosks. Data from low-income households in Nairobi indicate that about $30 \%$ of meat is sold in supermarkets and the rest through traditional outlets, mainly local markets (56). 
For dairy, the role of modern retailers is a bit stronger. In Ethiopia, the share of dairy sold through modern retail ranges between 33 and $98 \%$, highly depending on the product. While butter, yoghurt, and liquid milk are largely marketed through traditional outlets $(64-67 \%$ of total sales), cheese, powdered milk, and milk-based infant formula are sold mostly through modern suppliers (59-98\% of total sales) (50). In Kampala and Nairobi, low-income households were found to purchase most (70-85\%) of their milk and dairy products from traditional outlets; 15$30 \%$ was purchased from supermarkets (56).

\section{CEREALS AND LEGUMES}

While low-income households in Kampala did not purchase any of their cereals in supermarkets, supermarkets had a market share of about $20 \%$ for cereals among low-income Nairobi households, with the remaining $80 \%$ coming from traditional outlets. In both lowincome neighbourhood sites in Kampala and Nairobi, the largest shares of cereals (35-65\%) were marketed through 'mom and pop' stores. For legumes, nuts, and seeds, about $80 \%$ were bought from traditional outlets in both study sites (56).

Across all product categories, traditional retail is thus the most used market option by far, and it is particularly important for low-income households. In general, the less processed a food (e.g. fresh FV), the higher the share of products sold through traditional retail outlets. More highly processed products, including dairy, fortified cereals, bread, and pasta, are often bought through modern retailers. Most of these traditional outlets are SMEs (or micro-enterprises), making their importance in the retail segment undeniable.

\section{THE FLOW OF PRODUCTS ALONG THE FOOD VALUE CHAIN}

As demonstrated above, SMEs play a critical role in the production, processing, and marketing of FFV, meat, dairy, cereals, and legumes in Africa, particularly for low-income consumers. Building off the above analysis of single segments of the value chain, this section examines the flow of food products from producers and processers to retailers.

\section{FRUITS AND VEGETABLES}

\section{Micro-producers ( $<2 \mathrm{ha}$ )}

Micro-scale producers produce about one third of fresh FV in Africa (7). In the absence of data for fresh FV showing the flow between the different stages of the food value chain, assumptions based on beans and cowpeas in eastern Africa are extrapolated. Hence it is assumed that out of this production, about two-thirds (Figure 10) is used for subsistence consumption (44): it is consumed in the home, either unprocessed or after home-processing. The remaining one-third of the FV produced by smallholder farmers is either directly marketed through traditional retailers or marketed by traditional retailers after home processing or after being processed by SMEs. Less than $5 \%$ of the FV production is processed and/or marketed by large enterprises, usually through contract farming schemes (9). 
Fruits and vegetables

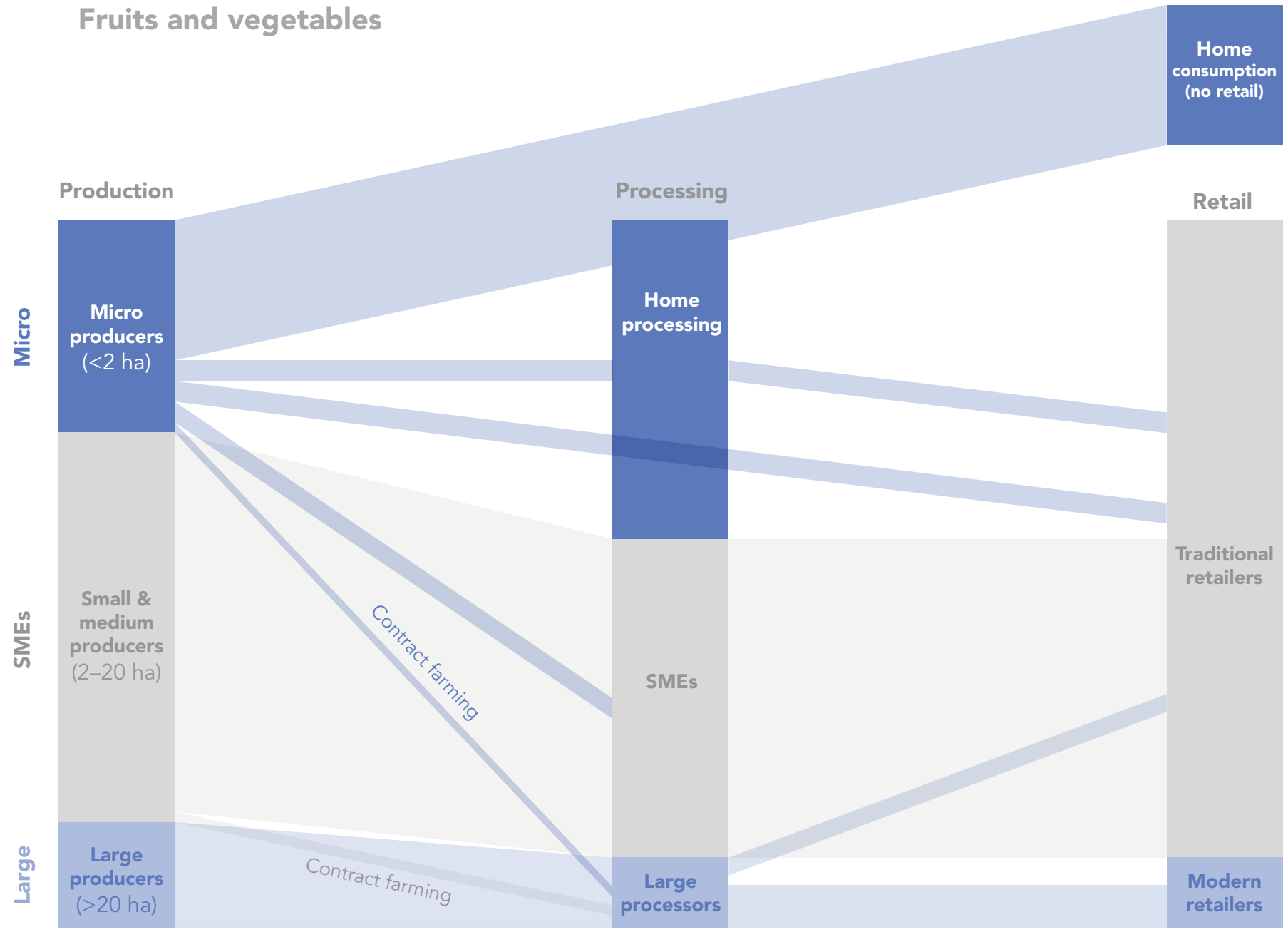

Figure 10. Flow between production, processing, and retail segments for fruits and vegetables in Africa. Own illustration based on data by Herrero et al. (7) (Africa /fruits and vegetables), Rusike et al. (44) (Kenya/beans and cowpeas), AGRA (9) (Africa/fruits and vegetables). Shares do not account for food waste and losses.

\section{Small and medium-sized producers (2 -20 ha)}

Small and medium-sized producers account for most FV production in Africa (about 55\%) (7). Since differentiated data on the amount of FV processing and the role of SMEs in the processing stage are missing, assumptions are based on general food processing SMEs in Africa. While it can be assumed that a large share of the FV production would be consumed or marketed unprocessed, most (about 95\%) of the FV that are produced by SMEs (and are being processed), are processed by SMEs and sold by retail SMEs. Only a small share (less than 5\%) is processed by large processors after being sourced through contract farming (9).

\section{Large producers (>20 ha)}

Large producers (>20 ha) contribute about $15 \%$ of the total FV in Africa (7). Based on general business assumptions for large-scale enterprises in Africa, it can be assumed that most of this produce is processed by large-scale processers and marketed through modern retailers; data on the share of unprocessed produce produced by large businesses are unavailable. A small share of FV processed by large processors might be marketed through traditional retailers, but the exact size of this share is unknown. 
Overall, most FV are produced, processed, and sold at the SME level. While there is substantial integration between micro/small producers and mid-chain and retail SMEs, the interaction between micro/small producers and processing SMEs with large processors and modern retail is still small (9).

\section{ANIMAL-SOURCE FOODS}

\section{Micro-producers}

Subsistence dairy farmers or livestock farmers in pastoral systems produce about $25-30 \%$ of the total livestock and dairy in Africa (7). Based on observations in Ethiopia, about $70-90 \%$ of dairy produced by micro-producers is either consumed directly in home or home processed and marketed as fresh milk, with $10-30 \%$ of milk produced being sold through informal or traditional markets, often without any processing (47) (Figure 11). ${ }^{21}$

\section{Animal source products}

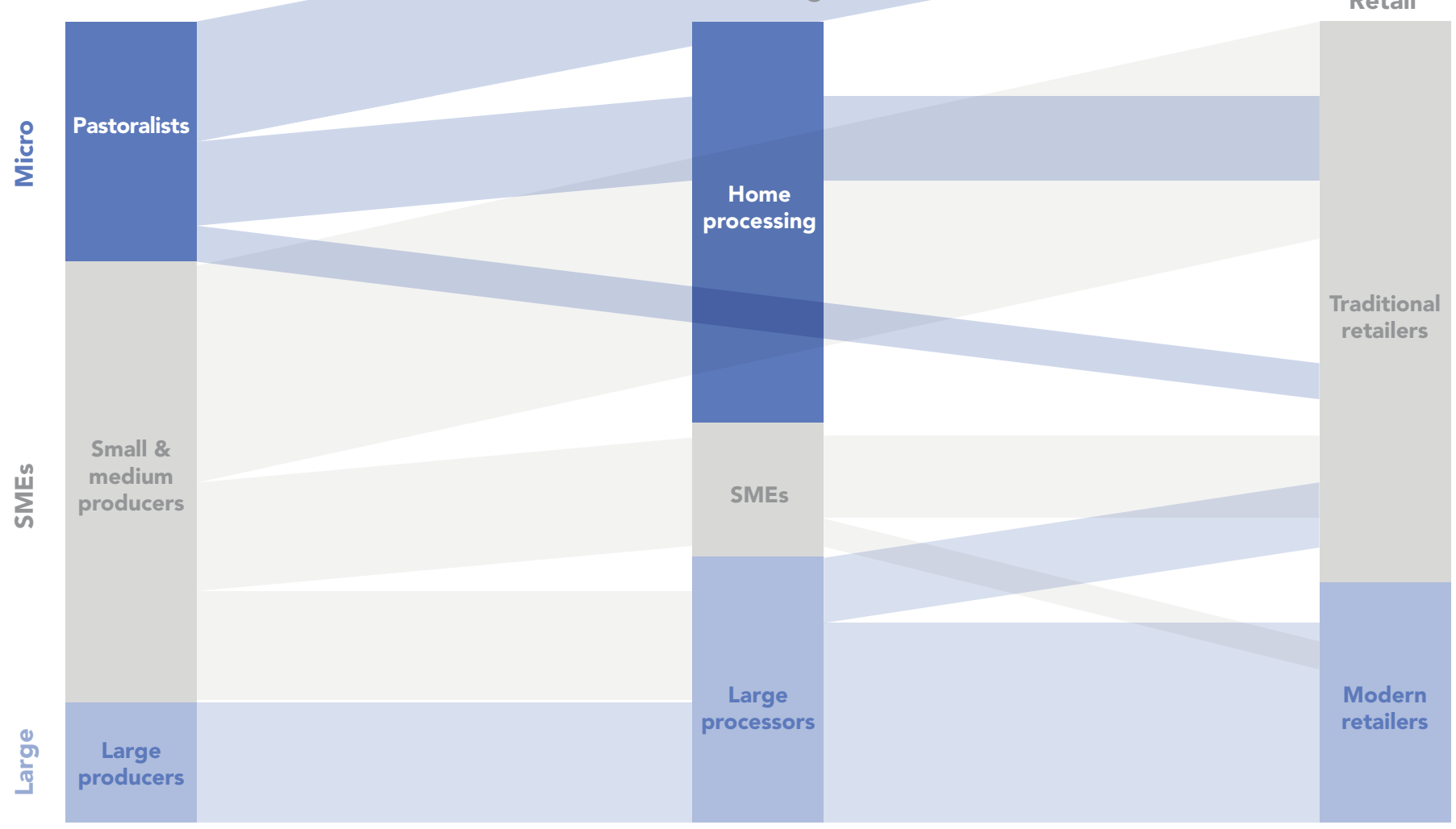

Figure 11. Flow between production, processing, and retail segments for ASF (mainly dairy) in Africa. Own illustration based on data by Herrero et al. (7) (Africa/livestock), Euromonitor (50) (Ethiopia/ dairy), Wanyama et al. (56) (Kenya, Uganda/meat, milk), Ndami et al. (47) (Africa/milk), Haggblade et al. (48) (Kenya/milk), and AGRA (9) (Africa/livestock). Illustration does not include data on fish. Shares do not account for food waste and losses.

21 Due to a lack of data for livestock and eggs, Figure 11 mainly relies on data for the dairy sector (production data is based on livestock, dairy, and eggs). 


\section{Small and medium-sized producers}

Commercial smallholder dairy farmers and small-to-medium size livestock farmers produce about 50-55\% of all animal-source products in Africa (7). For dairy, about half of this production is sold unprocessed, directly through informal or traditional markets. The other half is either processed by SMEs and sold by SMEs within the traditional retail sector or processed by large processors and sold by modern or traditional retail (48). While the few available examples from the meat sector in Kenya and Uganda suggest that meat is almost entirely marketed through traditional markets, milk is increasingly sold through modern retailers (56).

\section{Large producers}

Large manufacturers, including foreign multinationals, produce about $15-20 \%$ of all meat and dairy products in Africa (7). Based on universal business assumptions, it can be assumed that up to $100 \%$ of the commercially produced dairy is processed by large processors; most of this is sold through modern retail, but some is also sold by traditional retailers (48). Some large enterprises are also vertically integrated across the processing and retailing segments (e.g. through integrated butcheries in supermarkets (9)).

Overall, the picture for meat and dairy differs slightly from that of the FV sector: processing, when done, is done by large processors. Micro, small-, and medium-sized processors only play a minor role, but most meat and dairy products (especially meat) are marketed through SMEs (i.e. informal and traditional retailers). Some interactions between segments exist in the dairy sector, with medium-sized producers and processors providing milk to large processors and retailers, and large processors (including foreign multinationals) selling through traditional retailers; overall, up to $30 \%$ of dairy products are sold through modern retailers (56).

\section{CEREALS AND LEGUMES}

\section{Micro-producers ( $<2 \mathrm{ha}$ )}

Similar to for fruits and vegetables, about $30 \%$ of cereals and legumes in Africa are produced by smallholder farmers (i.e. those with less than 2 ha of land) (7). Based on data for selected African countries, ${ }^{22} 20-70 \%$ of this production (highly depending on the crop and local context) is consumed by the producers, either fresh or dried (Figure 12). Furthermore, it can be assumed that $30-80 \%$ of the cereals and legumes produced by micro-producers are processed, either at home or through SMEs, and then marketed through traditional retailers (44). Smallholder farmers may also supply to large processors under certain contractual arrangements, but AGRA estimates that on average the share of production being supplied to large enterprises is below 5\% (9).

\section{Small and medium producers (2 -20 ha)}

Over half of the total production of cereals and legumes comes from small and medium producers with farm sizes between 2-20 ha (7). Based on maize flour production in Tanzania, it can be assumed that most of this production is processed through SMEs and sold by traditional retailers (45). However, the SME sector also supplies large processors; for example, SMEs provide up to $70 \%$ of grain for large-scale fortification (according to data from Ethiopia (2018) (66)), either as raw grain or having already been processed by SMEs. Overall, SMEs

22 Kenya, Rwanda, Ghana, and Nigeria. 


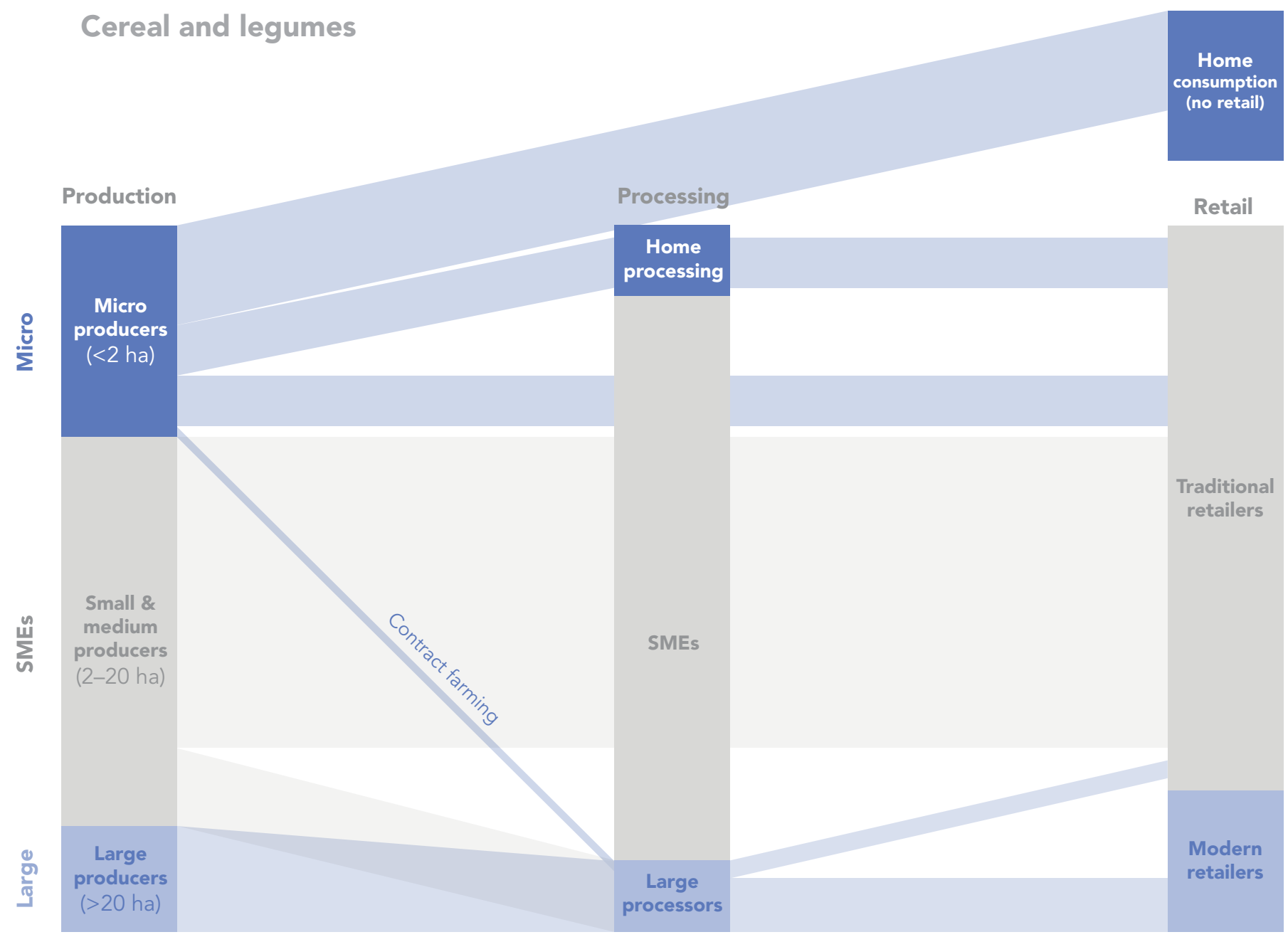

Figure 12. Flow between the production, processing, and retail segments for cereals and legumes in Africa. Own illustration based on data by Herrero et al. (7) (Africa/cereals and legumes), Rusike et al. (44) (Kenya, Rwanda, Ghana, Nigeria/grain legumes), Brooks-church (45) (Tanzania/maize), Hystra (66) (Ethiopia/fortification). Shares do not account for food waste and losses.

process about $95 \%$ of total cereals and legumes, with variation by type and setting (45). As for other food products, the share for cereals and legumes marketed by traditional retail is very high, about $80 \%$ (56). Retail SMEs are selling unprocessed or home processed cereals and legumes as well as those processed by large enterprises, but it can be assumed that most of the products come through the SME channel.

\section{Large producers (>20 ha)}

About $10-15 \%$ of cereals and legumes in Africa are produced by large producers (landholdings > 20 ha) (7). In general, the value chain remains exclusively within the large-scale sector, with most crops produced at a large scale being sent to large-scale processors, and finally sold through modern retailers. However, some large-scale-processed foods are also supplied to traditional retail outlets. Some large enterprises also use vertical integration to connect the processing and retailing segments (e.g. through integrated bakeries in supermarkets) (9). Especially for certain technically complex processing techniques, such as fortification, large processors play an important role, with shares of up to $100 \%$ depending on the food vehicle and local context (41). 
As for animal-source products, the cereal and legume sector has increasing levels of involvement of large processors and modern retailers. This is largely due to the large volumes of production in the cereals and legumes sector and the high degree of specialisation that some of that production requires. However, SMEs still play the largest role throughout the value chain.

\section{CONCLUSION}

This paper has sought to provide an overview of the involvement of SMEs in the food supply chain in Africa. Based on a review of existing data, the paper discussed the involvement of SMEs along the value chain, including in production, processing, and retail, as well as the flow between segments across these three stages. The analysis showed that, for all food groups examined, small and medium-scale producers provide the major part of supply. Over half of each food group examined is produced by small and medium-sized producers. At the processing stage, the involvement of SMEs was found to vary widely depending on the type of food, the country, and relevant regulations. While SMEs play an important role in the processing of cereals and legumes, their role in the meat and dairy sector is smaller; for the FV segment, there is very little processing. Overall, higher-value segments (e.g. milk pasteurisation, milk powder, yoghurt, cheese, and grain fortification) are dominated by bigger companies, including some SMEs but mainly large enterprises. For all food groups and particularly for low-income consumers, the traditional sector (i.e. kiosks, street vendors, open markets, and small shops) plays the most important role in food retail, indicating a large role for SMEs. While FV are almost exclusively sold through traditional channels, up to one third of dairy and processed cereal products are sold through modern retailers, often using vertical integration to connect processing and retailing segments (9).

Overall, the flow of products along food value chains demonstrates that SMEs are very important at all value chain stages. Their importance is not limited to raw, unprocessed foods and ingredients but also includes high-value products, like dairy and fortified cereals. In addition to their importance for production, processing, and retail, SMEs interact considerably with large enterprises as well as micro producers (i.e. smallholder farmers): 95\% of smallholder farmers sell part of their production to SME processors or wholesalers (9). Hence, SMEs both allow smallholder farmers to sell their produce and provide large enterprises with the inputs they need. As modern retailers only represent $10-20 \%$ (by value) of the agri-food sector in Africa, their capacity to integrate micro producers into their supply chains is very limited: less than $5 \%$ of smallholder farmers work under contract farming schemes with such retailers. While SME retailers are responsible for the remaining $80-90 \%$ of the food economy (by value), buying mainly from small-scale farmers, such arrangements are rarely formalised through contracts (9). Addressing this could be a potential opportunity to better link rural producers to urban markets.

This paper considered the food supply chain and its various stages broadly, purposefully choosing this non-targeted approach in orders to provide an overview. However, given the lack of data on many aspects of each food value chain stage, this overview is by no means complete. Overall, there is scarce literature on SMEs in Africa; when available, data are often outdated. This is partly due to a lack of transparent data policies. Prior research has also not used comparable approaches to analyse the available data. The analysis thus cannot claim to be representative of any specific supply chain stage or of the whole African continent. 
However, most of the examples shown here are relevant for African supply chains, in general, and provide a good overview of the importance of food system SMEs in African countries.

While the involvement of SMEs in some stages of the food value chain is still not sufficiently understood, this paper has indicated that SMEs are playing an active role in African food value chains and are highly important for production, processing, and retail, particularly for lowincome consumers. This underlines the importance of including SMEs in public- and privatesector efforts to increase the availability, accessibility, and affordability of nutritious foods. While SMEs in general are resourceful and dynamic, public infrastructure and policy investments are needed to help the private sector drive further agricultural transformation, open markets, and increase private investment in the sector. Roads, for example, can connect farmers to markets, increasing market supply and incomes and reducing food loss. Further growing the processing sector can add value to markets; expanding access to financing and putting in place policies and regulations to support the availability of raw materials can facilitate this. At the retail stage, policymakers can help increase food safety in informal markets, while supporting informal food vendors' livelihoods, through better urban planning and infrastructure as well as food safety training and informal sector-inclusive regulation. Jointly, an inclusive approach, encompassing SMEs at all steps in the value chain, can help drive the food system transformation need to achieve the SDGs and other global goals. 


\section{REFERENCES}

1. FAO, IFAD, UNICEF, WFP and WHO. The state of food security and nutrition in the world. 2019 Safeguarding against economic slowdowns and downturns. Rome, Italy: FAO; 2019.

2. Development Initiatives. Global Nutrition Report 2018: Shining a light to spur action on nutrition. Bristol, UK; 2018. (Development Initiatives).

3. HLPE. Nutrition and food systems [Internet]. Rome, Italy; 2017 p. 152. (High Level Panel of Experts on Food Security and Nutrition of the Committee on World Food Security). Available from: http://www.fao.org/cfs/cfs-hlpe/reports/en/

4. FAO. The future of food and agriculture: Alternative pathways to 2050 [Internet]. Rome, Italy; 2018 [cited 2019 Oct 2]. Available from: http://www.fao.org/publications/fofa/en/

5. Turner C, Aggarwal A, Coates J, Drewnoski A, Hawkes C, Herforth A, et al. Concepts and methods for food environment research in low and middle income countries [Internet]. London, UK: Agriculture, Nutrition and Health Academy Food Environments Working Group (ANH-FEWG). Innovative Methods and Metrics for Agriculture and Nutrition Actions (IMMANA) programme.; 2017 [cited 2019 Aug 27]. Available from: https://anh-academy. org/food-environments-technical-brief

6. Lowder SK, Skoet J, Raney T. The number, size, and distribution of farms, smallholder farms, and family farms worldwide. World Dev. 2016 Nov 1;87:16-29.

7. Herrero $M$, Thornton PK, Power B, Bogard JR, Remans R, Fritz S, et al. Farming and the geography of nutrient production for human use: a transdisciplinary analysis. Lancet Planet Health. 2017 Apr;1(1):e33-42.

8. Gómez MI, Ricketts KD. Food value chain transformations in developing countries: Selected hypotheses on nutritional implications. Food Policy. 2013 Oct;42:139-50.

9. AGRA. Africa Agriculture Status Report. The hidden middle: a quiet revolution in the private sector driving agricultural transformation. Nairobi, Kenya: Alliance for a Green Revolution in Africa (AGRA); 2019. Report No.: 7.

10. Abor A, Quartey P. Issues in SME development in Ghana and South Africa. Int Res J Finance Econ. 2010;39:218-28.

11. Smit $Y$, Watkins JA. A literature review of small and medium enterprises (SME) risk management practices in South Africa. Afr J Bus Manag. 2012; May 30;6(21):6324-30.

12. Gómez MI, Barrett CB, Buck LE, Groote HD, Ferris S, Gao HO, et al. Research principles for developing country food value chains. Science. 2011 Jun 3;332(6034):1154-5.

13. Vorst JGAJ van der, Da Silva CA, Trienekens JH. Agro-industrial supply chain management: concepts and applications. Rome: FAO; 2007.

14. Jayne TS, Chamberlin J, Traub L, Sitko N, Muyanga M, Yeboah FK, et al. Africa's changing farm size distribution patterns: the rise of medium-scale farms. Agric Econ. 2016 Nov;47(S1):197-214. 
15. HLPE. Investing in smallholder agriculture for food security [Internet]. Rome, Italy; 2013. Available from: http://www.fao.org/cfs/cfs-hlpe/reports/en/

16. Masters WA, Djurfeldt AA, De Haan C, Hazell P, Jayne T, Jirström M, et al. Urbanization and farm size in Asia and Africa: Implications for food security and agricultural research. Glob Food Secur. 2013 Sep 1;2(3):156-65.

17. Slavin JL, Lloyd B. Health benefits of fruits and vegetables. Adv Nutr. 2012 Jul 1;3(4):506-16.

18. Afshin A, Sur PJ, Fay KA, Cornaby L, Ferrara G, Salama JS, et al. Health effects of dietary risks in 195 countries, 1990-2017: a systematic analysis for the Global Burden of Disease Study 2017. The Lancet. 2019 May 11;393(10184):1958-72.

19. Willett W, Rockström J, Loken B, Springmann M, Lang T, Vermeulen S, et al. Food in the anthropocene: the EAT-Lancet Commission on healthy diets from sustainable food systems. The Lancet. 2019 Feb;393(10170):447-92.

20. FAOSTAT. New Food Balances (Preliminary data) [Internet]. 2020. Available from: http://www.fao.org/faostat/en/\#data/FBS

21. Wang $X$, Lin $X$, Ouyang $Y Y$, Liu J, Zhao G, Pan A, et al. Red and processed meat consumption and mortality: dose-response meta-analysis of prospective cohort studies. Public Health Nutr. 2016 Apr;19(5):893-905.

22. Tang M, Sheng X-Y, Krebs NF, Hambidge KM. Meat as complementary food for older breastfed infants and toddlers: A randomized, controlled trial in rural China. Food Nutr Bull. 2014 Dec;35(4 0):S188-92.

23. Hoddinott J, Headey D, Dereje M. Cows, missing milk markets, and nutrition in rural Ethiopia. J Dev Stud. 2015 Aug 3;51(8):958-75.

24. Hazell P. All-Africa review of experiences with commercial agriculture case study on livestock. 2007. (Background paper for the Competitive Commercial Agriculture in SubSaharan Africa (CCAA) Study).

25. African Union. The livestock development strategy for Africa (LiDeSA) 2015-2035 [Internet]. Nairobi, Kenya: Interafrican Bureau for Animal Resources; 2015 [cited 2019 Oct 7]. Available from: https://rr-africa.oie.int/docspdf/en/LiDeSA_ENG.pdf?

26. World Bank, FAO, ILRI, AU-IBAR. Investing in African livestock: business opportunities in 2030-2050. 2013 p. 14.

27. Gertenbach W. Dairy farming in South Africa - where to now? Food and Agriculture Organization of the United Nations; 2006.

28. Food and Agriculture Organization of the United Nations. Data. Crops. [Internet]. FAOSTAT. 2020. Available from: http://www.fao.org/faostat/en/\#data/OC

29. Food and Agriculture Organization of the United Nations. Data. Food Balance Sheets [Internet]. FAOSTAT. 2019. Available from: http://www.fao.org/faostat/en/\#data/QC 
30. World Bank. World Bank list of economies [Internet]. 2019. Available from: https:// datahelpdesk.worldbank.org/knowledgebase/articles/906519-world-bank-country-andlending-groups

31. HLPE. Food losses and waste in the context of sustainable food systems. Rome, Italy: FAO; 2014 p. 117.

32. Karlovsky P, Suman M, Berthiller F, De Meester J, Eisenbrand G, Perrin I, et al. Impact of food processing and detoxification treatments on mycotoxin contamination. Mycotoxin Res. 2016;32(4):179-205.

33. Musyoka JN, Abong' GO, Mbogo DM, Fuchs R, Low J, Heck S, et al. Effects of acidification and preservatives on microbial growth during storage of orange fleshed sweet potato puree. Int J Food Sci [Internet]. 2018 Jun 7 [cited 2020 Feb 20];2018. Available from: https://www.ncbi.nlm.nih.gov/pmc/articles/PMC6011086/

34. Webster JL, Dunford EK, Neal BC. A systematic survey of the sodium contents of processed foods. Am J Clin Nutr. 2010 Feb 1;91(2):413-20.

35. Kang M-H, Yoon K-S. Elementary school students' amounts of sugar, sodium, and fats exposure through intake of processed food. J Korean Soc Food Sci Nutr. 2009;38(1):52-61.

36. Malagié M, Jensen G, Graham J, Smith D. Chapter 67 - Food industry. Food industry processes. In: Berkowitz D, editor. Encyclopaedia of Occupational Health and Safety [Internet]. 4th ed. 2012. Available from: https://www.iloencyclopaedia.org/

37. UNIDO. Agribusiness Development [Internet]. 2013 [cited 2019 Nov 6]. Available from: https://www.unido.org/sites/default/files/2013-01/UNIDO_Agribusiness_development_0.pdf

38. Osendarp SJM, Martinez H, Garrett GS, Neufeld LM, De-Regil LM, Vossenaar M, et al. Large-scale food fortification and biofortification in low- and middle-income countries: a review of programs, trends, challenges, and evidence gaps. Food Nutr Bull. 2018 Jun $1 ; 39(2): 315-31$.

39. Minister of Health, Uganda. Statutory Instruments 2011 No. 53. Food and Drugs (Food Fortification) (Amendment) Regulations. 2011.

40. Minister for Health and Social Welfare, Tanzania. Government Notice No. 205. The Tanzania Food, Drugs and Cosmetics Act (Cap.2019). 2011.

41. Mkambula P. RE: Data on SMEs in the processing sector. 2019.

42. Akinnifesi FK, Kwesiga F, Mhango J, Chilanga T, Mkonda A, Kadu CAC, et al. Towards the development of miombo fruit trees as commercial tree crops in southern Africa. For Trees Livelihoods. 2006 Jan;16(1):103-21.

43. Lenné JM, Ward AF. Improving the efficiency of domestic vegetable marketing systems in east Africa: constraints and opportunities. Outlook Agric. 2010 Mar;39(1):31-40. 
44. Rusike J, van den Brand G, Boahen S, Dashiell K, Kantengwa S, Ongoma J, et al. Value chain analyses of grain legumes in N2Africa. Kenya, Rwanda, eastern DRC, Ghana, Nigeria, Mozambique, Malawi and Zimbabwe. www.N2Africa.org; 2013 p. 96.

45. Brooks-Church F. Q4 Sanku-PHC report (reaching 2 million people). 2019.

46. Wageningen University. Business opportunities. Food processing in Ethiopia. 2013.

47. Ndami O, Hemme T, Latacz-Lohmann U. Dairying in Africa - Status and recent developments. Livest Res Rural Dev [Internet]. 2007 [cited 2019 Nov 22];19(111). Available from: http://www.Irrd.org//rrd19/8/ndam19111.htm

48. Haggblade S, Thériault V, Staatz J, Dembele N, Diallo B. A conceptual framework for promoting inclusive agricultural value chains. International Fund for Agricultural Development; 2012.

49. Mbowa S. Expansion of the product space in Uganda's dairy value chain. Economic Policy Research Centre (EPRC); 2019.

50. Euromonitor. Dairy in Ethiopia. Data compiled by Euromonitor for GAIN in July 2019. 2019.

51. Seck M, Marshall K, Fadiga ML. Policy framework for dairy development in Senegal. Addis Ababa, Ethiopia: International Livestock Research Institute; 2016.

52. Oxfam. Europe's Dairy Sector has its eyes on West Africa [Internet]. 2016 [cited 2020 Feb 4]. Available from: https://gchoplinenglish.files.wordpress.com/2016/11/2016-study-milkwest-africa-oxfam-sosfaim.pdf

53. Demmler KM, Ecker O, Qaim M. Supermarket shopping and nutritional outcomes: a panel data analysis for urban Kenya. World Dev. 2018 Feb 1;102:292-303.

54. Demmler KM, Klasen S, Nzuma JM, Qaim M. Supermarket purchase contributes to nutrition-related non-communicable diseases in urban Kenya. PLOS ONE. $2017 \mathrm{Sep}$ $21 ; 12(9): \mathrm{e} 0185148$.

55. Khonje MG, Qaim M. Modernization of African food retailing and (un)healthy food consumption. Sustainability. 2019 Jan;11(16):4306.

56. Wanyama R, Gödecke T, Chege CGK, Qaim M. How important are supermarkets for the diets of the urban poor in Africa? Food Secur [Internet]. 2019 Sep 7 [cited 2019 Sep 20]; Available from: https://doi.org/10.1007/s12571-019-00974-3

57. Anbarci N, Gomis-Porqueras P, Pivato M. Formal and informal markets: A strategic and evolutionary perspective. Munich Pers RePEc Arch. 2012;(42513):31.

58. Roesel K, Grace D, editors. Food safety and informal markets: animal products in SubSaharan Africa. London; New York: Routledge, Taylor \& Francis Group; 2015.

59. Traill WB, Mazzocchi M, Shankar B, Hallam D. Importance of government policies and other influences in transforming global diets. Nutr Rev. 2014 Sep;72(9):591-604. 
60. Reardon T, Timmer C, Minten B. Supermarket revolution in Asia and emerging development strategies to include small farmers. Proc Natl Acad Sci. 2012;109(31):12332-7.

61. Rischke R, Kimenju SC, Klasen S, Qaim M. Supermarkets and food consumption patterns: the case of small towns in Kenya. Food Policy. 2015 Apr;52:9-21.

62. Grace D. Food safety in low and middle income countries. Int J Environ Res Public Health. 2015 Sep;12(9):10490-507.

63. Chege CGK, Andersson CIM, Qaim M. Impacts of supermarkets on farm household nutrition in Kenya. World Dev. 2015 Aug;72:394-407.

64. Schipmann C, Qaim M. Supply chain differentiation, contract agriculture, and farmers' marketing preferences: the case of sweet pepper in Thailand. Food Policy. 2011 Oct;36(5):667-77.

65. Reardon T, Timmer CP, Barrett CB, Berdegué J. The rise of supermarkets in Africa, Asia, and Latin America. Am J Agric Econ. 2003;85(5):1140-1146.

66. Hystra. Study on nutritious foods in Ethiopia. UK AID; 2018. 